\title{
FÁCIES DELTAICAS DEVONIANAS DE JACIARA - MATO GROSSO: O INDÍCIO DE UMA NOVA PROPOSTA ESTRATIGRÁFICA PARA A SUB- BACIA DE ALTO GARÇAS
}

\author{
DEVONIAN DELTAIC FACIES OF JACIARA - MATO GROSSO: INDICATION OF A NEW \\ STRATIGRAPHIC PROPOSAL FOR THE ALTO GARÇAS SUB-BASIN
}

\section{Victor Rodrigues RIBEIRO' ${ }^{1}$, Renato Pirani GHILARDI ${ }^{2}$, Silane Aparecida FERREIRA DA SILVA CAMINHA ${ }^{3}$}

${ }^{1}$ Pós-Graduação em Biociências, Faculdade de Ciências e Letras, Universidade Estadual Paulista Júlio de Mesquita Filho, Campus de Assis, Avenida Dom Antônio, 2100, Assis, São Paulo. E-mail: victor18lapalma@gmail.com

${ }^{2}$ Departamento de Ciências Biológicas, Faculdade de Ciências, Universidade Estadual Paulista Júlio de Mesquita Filho, Campus de Bauru, Avenida Engenheiro Luiz Edmundo Carrijo Coube, 1401, Bauru, São Paulo. E-mail: renato.ghilardi@unesp.br ${ }^{3}$ Faculdade de Geociências, Universidade Federal de Mato Grosso, Avenida Fernando Correia da Costa, 2387, Boa Esperança, Cuiabá, Mato Grosso. E-mail: silane.silva@gmail.com

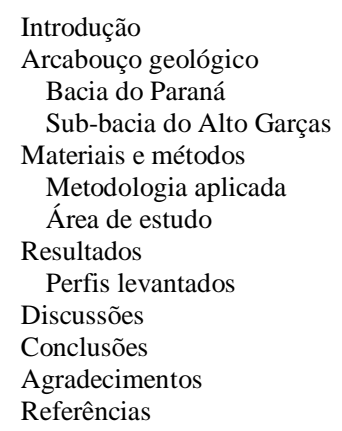

RESUMO - O Devoniano da bacia do Paraná é caracterizado pela consolidação de duas sub-bacias, uma ao sul chamada sub-bacia Apucarana e outra ao norte chamada sub-bacia Alto Garças. Diferenças paleoambientais são notadas em ambas bacias, na sub-bacia Alto Garças as diferenças são laterais: fácies terrígenas deltáicas se estabeleceram na margem norte enquanto que fácies marinhas reinam à noroeste. Na região de Jaciara-MT, flanco noroeste da sub-bacia Alto Garças, as rochas devonianas aflorantes foram descritas apenas contendo fácies de mar aberto, no entanto aqui apresentamos novos empilhamentos estratigráficos, ambientes deposicionais e concentrações fossilíferas. Foram individualizados várias subunidades deposicionais, sendo elas da base para o topo; fácies de mar aberto com fósseis bastante representativos da fauna Malvinocáfrica (exemplares de Lingulídeos, Orbiculoidea sp., Australocoelia sp., Notiochonetes sp. e Australospirifer sp.), fácies de frente deltaica influenciada pela ação das marés, fácies de preenchimentos de vales incisos, fácies de rompimentos cíclicos de diques marginais sob planícies deltaicas, fácies fluviais, fácies transgressivas marinhas. Delimitadas por Superfície de Inundação Máxima, Superfície de Regressão Forçada e a Superfície Transgressiva.

Palavras Chave: Sub-bacia Alto Garças. Estratigrafia. Devoniano. Mato Grosso. Brasil.

\begin{abstract}
The Devonian of the Paraná basin is characterized by the consolidation of two sub-basins, one in the south called Apucarana sub-basin and another in the north called Alto Garças sub-basin. Paleoenvironmental differences are noted in both basins, in the Alto Garças sub-basin the differences are lateral: deltaic facies settled on the northern shore while marine facies reigned to the northwest. In the Jaciara-MT region, northwestern flank of the Alto Garças sub-basin, the outlying Devonian rocks were described only with open sea facies, however here we present new stratigraphic stacks, depositional environments and fossiliferous concentrations. Several depositional subunits were individualized, from the base to the top; facies of open sea with very representative fossils from the fauna Malvinokaffric (specimens of Lingulídeos, Orbiculoidea sp., Australocoelia sp., Notiochonetes sp. and Australospirifer sp.), facies from deltaic front influenced by the action of the tides, facies of incised valleys, facies of ruptures cyclic dikes of deltaic plains, fluvial facies, facies of marine transgressions. Bounded by Maximum Flood Surface, Forced Regression Surface and Transgressive Surface.
\end{abstract}

Keywords: Alto Garças Sub-basin. Stratigraphy. Devonian. Mato Grosso. Brazil.

\section{INTRODUÇÃO}

A Bacia do Paraná consiste em um pacote sedimentar com rochas que datam do Ordoviciano ao Cretáceo, subdividido por discordâncias temporais, as quais delimitam supersequências de deposição sedimentar (Milani et al., 2007). Durante o Devoniano, os níveis de subsidência e soerguimento eram desiguais nesta vasta bacia, gerando assim, duas sub-bacias: uma ao sul denominada de sub-Bacia Apucarana, a qual aflora nos estados do Rio Grande do Sul, Santa Catarina, Paraná e outras regiões do Uruguai; e a outra sub-bacia ao norte, denominada de sub- 
bacia Alto Garças, onde são descritos afloramentos nos estados de Goiás, Mato Grosso e Mato Grosso do Sul (Ramos, 1970).

No que diz respeito às diferenças paleoambientais da sub-bacia de Alto Garças durante o Devoniano, Andrade \& Camarço (1980) descreveram fácies pelíticas com siltitos e folhelhos predominando nas porções mais profundas da bacia, bem representadas no flanco noroeste (Estados de Mato Grosso e Mato Grosso do Sul). Em direção ao flanco norte (Estado de Goiás), os sedimentos configuram pacotes mais arenosos terrígenos (arenitos de tamanhos diversos e conglomerados) de origem deltaica, associados a pacotes heterolíticos de rompimento de diques marginais.

O panorama paleoclimático também deve ser ressaltado pois durante o Devoniano os continentes sul-americano, africano, australiano e antártico ocupavam regiões polares, abaixo dos círculos tropicais e equatoriais, propiciando condições climáticas similares às que são vistas hoje nos mares gelados do círculo polar antártico e ártico (Scotese \& McKerrow, 1990).

A área de pesquisa está inserida ao município de Jaciara, aproximadamente $146 \mathrm{~km}$ a leste da capital de Mato Grosso, Cuiabá. A região está localizada na borda noroeste da bacia do Paraná, onde ocorrem afloramentos do Grupo Paraná (Assine, 1996; Andrade \& Camarço, 1980; Melo, 1988; Grahn et. al. 2010), no entanto pouco tem sido discutido nesse flanco da bacia nos últimos anos. Tendo em vista a problemática supracitada, este trabalho vem trazer a descrição e a interpretação de novos afloramentos do flanco nordeste da bacia do Paraná, apresentar as assembleias fossilíferas, bem como propor uma possível estratigrafia nova para a sub-Bacia de Alto Garças.

\section{ARCABOUÇO GEOLÓGICO}

\section{Bacia do Paraná}

A Bacia do Paraná possui pacotes sedimentares e magmáticos com espessura de aproximadamente 7 mil metros, com eixo Norte-Sul e formato ovalado, ocupando uma área de aproximadamente 1,5 milhões de quilômetros quadrados. É possível encontrar rochas desta bacia nos estados de Mato Grosso, Mato Grosso do Sul, Goiás, São Paulo, Paraná, Minas Gerais, Santa Catarina e Rio Grande do Sul, além do norte do Uruguai, nordeste da Argentina e o leste paraguaio (Milani et al., 2007).

Milani (1997) individualiza seis unidades deposicionais, ou Supersequências para a bacia. A Supersequência Paraná é caracterizada por condições climáticas temperadas e abarca o segundo ciclo completo de transgressão-regressão da bacia, o qual se iniciou no Lochkoviano e terminou no Frasniano não terminal, de modo geral o devoniano da bacia é individualizado em duas Formações, sendo a basal chamada de Furnas, sobreposta pela Formação Ponta Grossa.

A sucessão de fácies sedimentares que constituem a Formação Furnas é caracterizada por sedimentos grossos na base e mais finos no topo sugerindo um afogamento progressivo da plataforma arenosa que teria sido finalizado com a deposição de sedimentos marinhos (camada de transição). No topo tem-se a deposição pelítica da Formação Ponta Grossa, com intervalos de progradações arenosas (Milani et al., 2007).

Ramos (1970) descreve os eventos tectônicos durante o Paleozoico no Brasil a partir de isópacas, evidenciando que durante o Devoniano duas subbacias são geradas, devido a valores desiguais de subsidência e de soerguimento, as denominadas sub-bacia de Alto Garças, ao norte, e sub-bacia de Apucarana, ao sul, individualizadas pelos altos de Três Lagoas e de Campo Grande.

\section{Sub-Bacia Alto Garças}

Andrade \& Camarço (1980) propõem uma estratigrafia para sub-bacia Alto Garças à partir de poços perfurados e afloramentos nos estados de Mato Grosso e Goiás, sendo a base caracterizada pela Formação Furnas e o topo a Formação Ponta Grossa. Segundo Ramos (1970) e Andrade \& Camarço (1980) a Formação Furnas ocorre em toda a extensão da bacia, com predominância de arenitos oriundos de um paleoambiente fluvial entrelaçado com pouca influência marinha.

Já a Formação Ponta Grossa possui três membros: a-Membro Inferior, com predominância de pelitos e arenitos lenticulares subordinados provenientes de um ambiente marinho; b- Membro Médio, ocorrendo apenas na borda norte da bacia, no Estado de Goiás, caracterizado como arenitos avermelhados grossos de um sistema deltaico, continental. À medida que se desloca para a borda nordeste (estados de Mato Grosso e Mato Grosso do Sul) o Membro Inferior estaria em contato direto com o Membro Superior; c-Membro Superior, identificado em toda a porção da bacia, caracterizados como uma grande parassequência granodecrescente de arenitos finos gradando para folhelhos cinza escuros. 
Melo (1988) propõe a utilização de uma nomenclatura para a sub-bacia Alto Garças que vai de concordância com a proposta por Andrade \& Camarço (1980), no entanto o que antes era chamado de Formação Furnas foi denominado de Unidade Chapada 1, o Membro Inferior da Formação Ponta Grossa de Unidade Chapada 2, o Membro Médio de Unidade Chapada 3 e o Membro Superior de Unidade Chapada 4.

Assine (1996) propõe que as nomenclaturas empregadas na sub-bacia de Apucarana sejam também empregadas na sub-bacia de Alto Garças, assim, a Unidade Chapada 2 seria chamada de Membro Tibagi e a Unidade Chapada 4 seria o Membro São Domingos, esta proposta reafirmada por Milani et al. (2007). Por fim, Grahn et. al. (2010) utilizando análises palinológicas de diversos pontos nos estados de Goiás e Mato Grosso, delimitam idades para as unidades, sendo elas da base para o topo: Unidade 1, Lochkoviano; Unidade 2, final do Pragiano e começo do Emsiano; Unidade 2 e 3 Eifeliano e Unidade 4, Givetiano e Frasniano.

\section{MATERIAIS E MÉTODOS}

\section{Metodologia Aplicada}

Inicialmente, um estudo bibliográfico a respeito da região em discussão foi efetuado e duas vertentes foram levantadas: uma geológica, onde os artigos e teses a respeito da geologia regional e local foram fichados (Ramos, 1970; Andrade \& Camarço, 1980; França \& Potter, 1988; Melo, 1988; Renne et al., 1992; Assine, 1996; Fernandes \& Coimbra, 2000; Milani, 2007; Grahn et al., 2010); e uma segunda vertente paleontológica/tafonômica, onde foram fichados artigos e teses que continham assembléias fossilíferas e procedimentos de coleta nas unidades geológicas devonianas da Bacia do Paraná (Boucot et al., 1971; Quadros, 1979; Andrade \& Camarço, 1980; Melo, 1988; Simões \& Ghilardi, 2000; Grahn et al., 2010; Bosetti et al., 2012; Carbonaro \& Ghilardi, 2016). Nas etapas de campo foram coletadas informações tais como litologias, estruturas, paleocorrentes (quando aplicável), dimensões, espessuras das camadas e dos afloramentos. Também foram feitas coletas paleontológicas segundo a metodologia de Simões \& Ghilardi (2000) onde foram delimitados quadrados de $2 \mathrm{~m}$ de largura por $2 \mathrm{~m}$ de altura nos afloramentos com as maiores concentrações fossilíferas, a coleta ocorreu da base para o topo dos pacotes, conjunta à descrição litológica e a identificação prévia dos fósseis.

\section{Área de Estudo}

A área de estudo está na porção sudeste do estado de Mato Grosso, inserida em parte da Folha Dom Aquino (SD. 21-Z-D). Os pontos levantados estão dispostos ao longo da BR-364, dentro das delimitações do município de Jaciara e o acesso ao local pode ser feito a partir de Cuiabá, percorrendo cerca de $150 \mathrm{~km}$ sentido Rondonópolis (Figura 1). Os afloramentos aqui apresentados são nomeados seguindo a proximidade ao perímetro urbano de Jaciara, sendo eles AJ-01, AJ-02, AJ-03, AJ-04 e AJ-05.

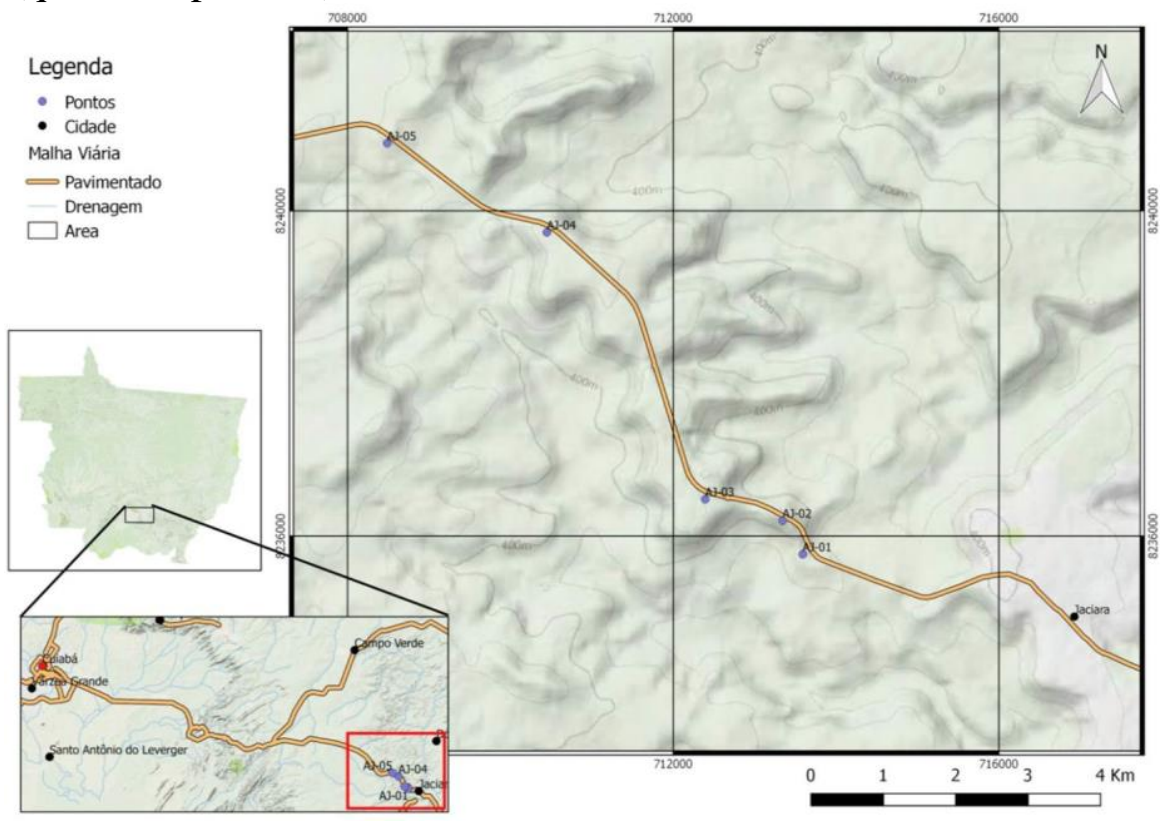

Figura 1 - Mapa de localização da área estudada com afloramentos levantados. 


\section{RESULTADOS}

\section{Perfis dos Afloramentos}

Ponto AJ-01 (Coordenadas UTM 713590 E, $8235779 \mathrm{~N}, 415 \mathrm{~m})$

Este talude possui orientação EW/N30W, está localizado próximo a entrada da Pousada Rosa dos Ventos na BR-364 e tem aproximadamente 8,5 m de altura e $150 \mathrm{~m}$ de largura.

As rochas aflorantes são predominantemente pelíticas, sendo elas da base para o topo: um pacote de siltito cinza-esbranquiçado finamente laminado com 2,7 $\mathrm{m}$ de espessura e presença de esfenotalos no topo; uma fina camada de folhelho cinza escuro laminado com $20 \mathrm{~cm}$ de espessura; uma camada de arenito muito fino amarelado com $2 \mathrm{~m}$ de espessura, estratificação plano paralela e marcas onduladas na base que passa para estratificações cruzadas tabulares no topo e esporádicas marcas onduladas simétricas; sobrepondo todos os pacotes, um espesso pacote de siltito cinza-esbranquiçado de $3,5 \mathrm{~m}$ de espessura, com estratificações plano paralelas, ocorrência de crinóides, esfenotalos e braquiópodes lingulídeos, no primeiro metro deste pacote e há uma fina lente de arenito muito fino amarelado (Figura 2).

Ponto AJ-02 (Coordenadas UTM 713342 E, $8236192 \mathrm{~N}, 423 \mathrm{~m})$

Este ponto apresenta o maior afloramento identificado na área, com aproximadamente $19 \mathrm{~m}$ de altura e $420 \mathrm{~m}$ de largura, orientado S30E/N65W.

Da base para o topo do talude foi observado um pacote de $6 \mathrm{~m}$ de siltitos cinzasesbranquiçados finamente laminados gradando sutilmente para folhelhos cinza-escuro no topo. Também foram observados lingulídeos, Orbiculoidea sp. Notiochonetes sp., espécies da superfamília Mutattionellidae, Australocoelia sp., além de icnofósseis, crinóides, bivalves, trilobitas e esfenotalos.

Em $6 \mathrm{~m}$ há uma fina camada de arenito fino de $60 \mathrm{~cm}$ de espessura, coloração amarelaesbranquiçada e estratificação cruzada tabular, sobreposta por uma camada de siltito cinza-claro com estratificação plano-paralela de $1,60 \mathrm{~m}$ de espessura (Figura 3).

Nos 6,5 m subsequentes, há alternância de siltitos, folhelhos e arenitos finos, visto que nos primeiros $3,5 \mathrm{~m}$ ocorrem siltitos vermelhoamarelados, folhelhos cinza-esverdeados e finas lâminas de arenitos muito finos amarelados, e em todas as camadas ocorrem estratificações cruzadas do tipo hummocky, marcas onduladas simétricas esporádicas, estratificações plano paralelas nos folhelhos e nos siltitos, além de icnofósseis do tipo Cruziana.

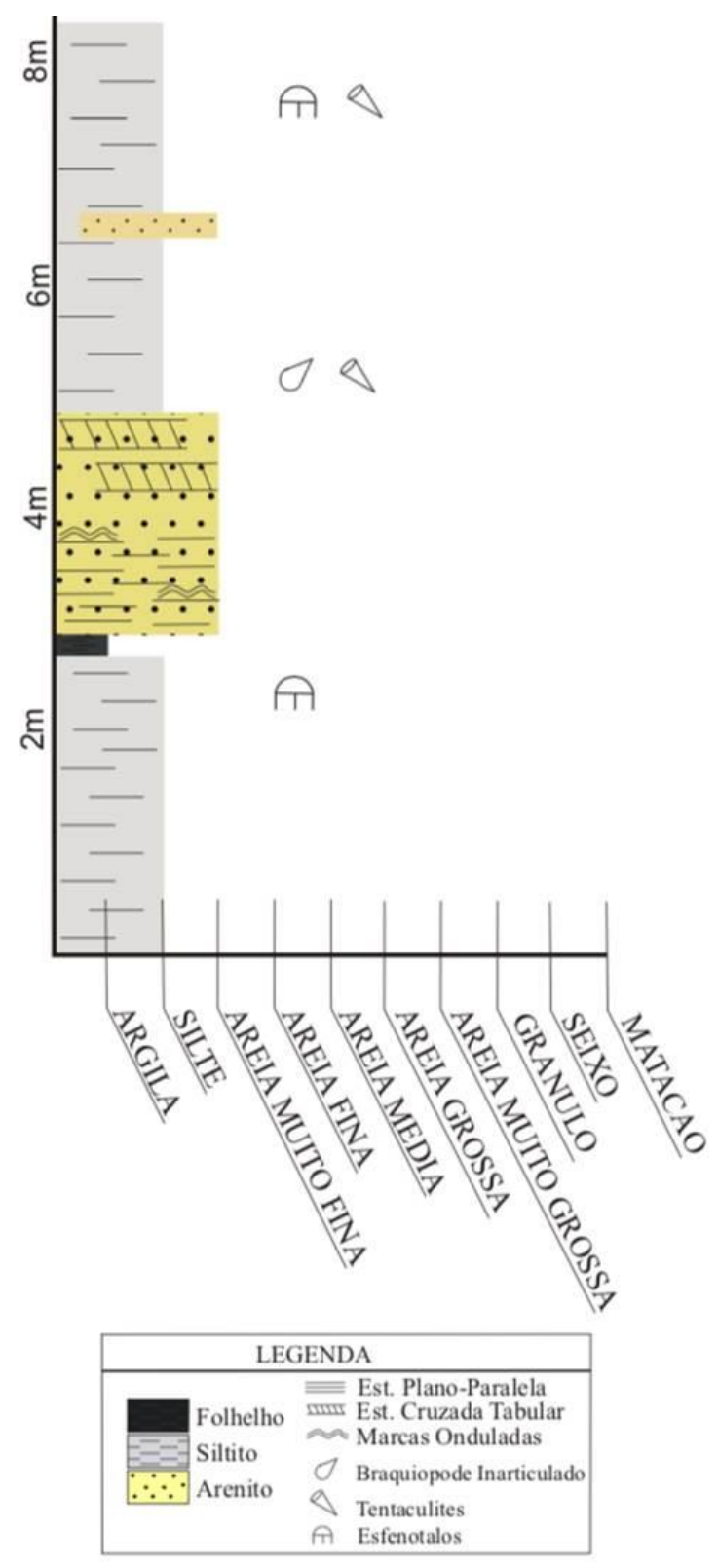

Figura 2 - Coluna estratigráfica do afloramento AJ-01.

Já os outros $3 \mathrm{~m}$ ocorrem siltitos avermelhados com estratificações plano paralelas e arenitos amarelados finos com estratificação cruzada tabular com algumas porções bioturbadas, sendo que nos siltitos foram identificados icnofósseis do tipo Cruziana concordantes com o acamamento das rochas. Na porção mediana deste pacote alternado, há uma lente de 1,3m de espessura de arenito amarelo-claro granodecrescente (arenito médio para arenito muito fino) com estratificações cruzadas acanaladas, bioturbações e icnofósseis foram identificadas no topo da lente, a qual possui uma estrutura de escavação nítida. 


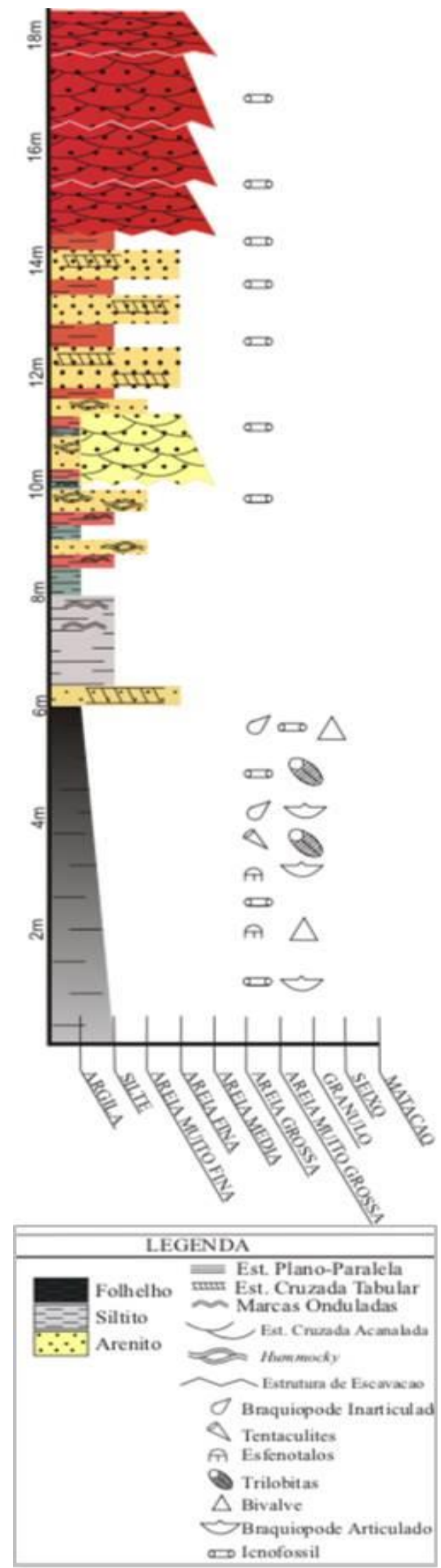

Figura 3 - Coluna estratigráfica do afloramento AJ-02.

No topo do talude ocorrem quatro pacotes de arenitos médios a finos granodecrescentes com espessuras variadas $(1,20 \mathrm{~m}, 1 \mathrm{~m}, 1,40 \mathrm{~m}$ e 80 $\mathrm{cm}$, da base para o topo), coloração avermelhada e icnofósseis do tipo Skolithos e estratificações cruzadas acanaladas. A base destes sempre tem estruturas de escavação e nos últimos $1,5 \mathrm{~m}$ do pacote ocorre uma camada irregular ferruginosa com aproximadamente $6 \mathrm{~cm}$ de espessura.

Ponto AJ-03 (Coordenadas UTM 712393 E, $8236455 \mathrm{~N}, 505 \mathrm{~m}$ )

Este outro talude possui uma altura máxima de $12 \mathrm{~m}$ e aflora por aproximadamente $200 \mathrm{~m}$ ao longo da rodovia, sua orientação varia de EW/N65W.

Da base para o topo, uma camada de aproximadamente $2 \mathrm{~m}$ de espessura de arenito grosso a médio granodecrescente, coloração avermelhada, com duas lentes irregulares ferruginosas de $5 \mathrm{~cm}$ de espessura no topo do pacote. Sobrepondo há uma sequência de aproximadamente $2 \mathrm{~m}$ de espessura alternada de siltitos avermelhados com estratificação plano paralela, arenitos médios cinzas e folhelhos cinza-escuro com marcas onduladas e estratificação plano paralela, as camadas de arenito mais superior possuem estratificações cruzadas tabulares e bioturbações.

Diversos pacotes alternados de siltitos, arenitos e lentes de conglomerado compõem um pacote de $5 \mathrm{~m}$ de espessura. Nos primeiros $3 \mathrm{~m}$ tem-se a alternância de siltitos avermelhados com estratificações plano-paralelas e três pacotes de arenito médio com espessuras variadas $(1 \mathrm{~m}$, $80 \mathrm{~cm}$ e $50 \mathrm{~cm}$, da base para o topo), de cor cinza, estratificação plano-paralela, esporádicas estratificações cruzadas acanaladas, marcas onduladas esparsas, considerável nível de bioturbação, nódulos de manganês no pacote inferior e o arenito mediano possui uma matriz ferruginosa; as lentes de conglomerado polimítico de arcabouço aberto ocorrem em todos os pacotes de arenitos, os grãos destes conglomerados possuem litologias de arenitos e siltitos, a matriz possui granulometria areia média de coloração avermelhado esparsas imersas nos arenitos.

Nos subsequentes outros $2 \mathrm{~m}$ dos pacotes alternadas ocorrem siltitos avermelhados com estratificação plano-paralela e icnofósseis; alternando com dois pacotes de arenitos médios cinza claro (um de $0,50 \mathrm{~cm}$ e outro de $0,80 \mathrm{~cm}$ de espessura), no pacote menor há estratificação cruzada acanalada, restos de vegetais e marcas onduladas, já no pacote maior as estratificações são do tipo plano-paralelas, e em ambos os pacotes foram encontrados restos de vegetais. 
Sobrepondo esta seção, três camadas de arenitos cinza-amarelados de granulometria média a fina granodecrescentes com espessuras de $50 \mathrm{~cm}, 80 \mathrm{~cm}$ e $70 \mathrm{~cm}$, nas porções basais dos pacotes há bioturbação intensa, o pacote inferior possui estratificações plano-paralelas e os pacotes superiores é notória estratificações cruzadas acanaladas (Figura 4).

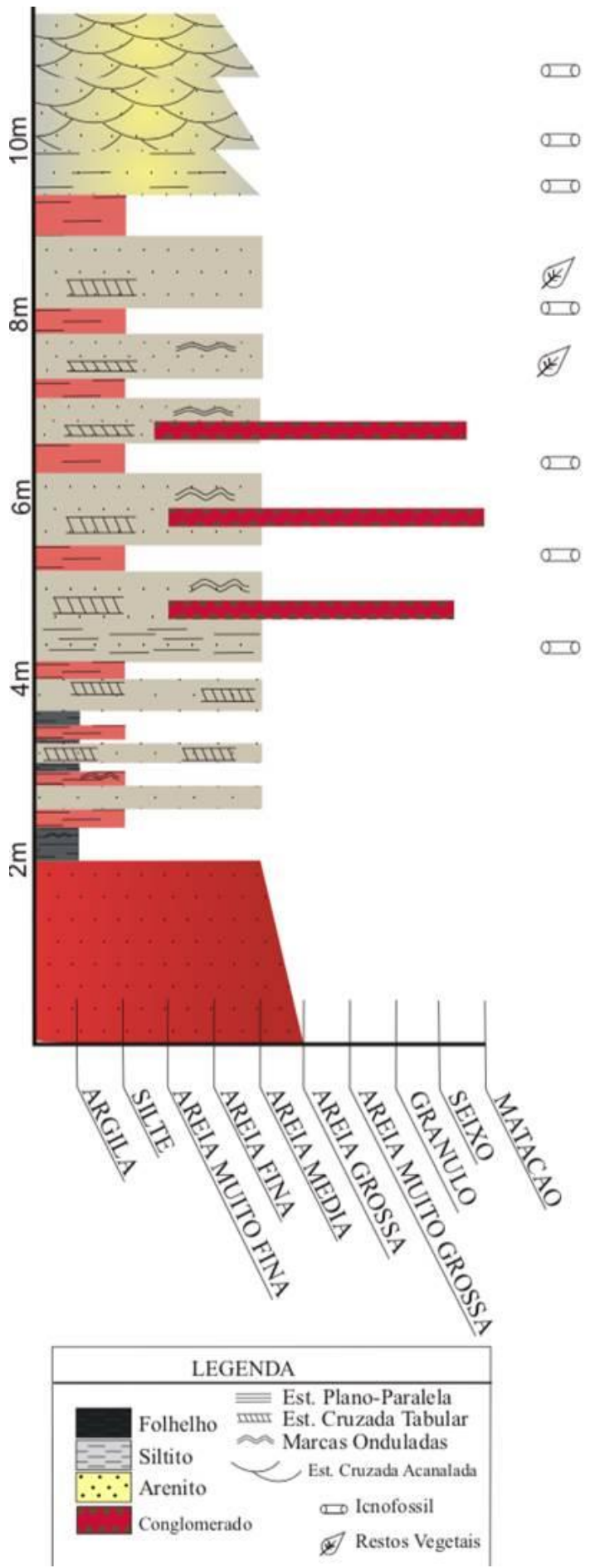

Figura 4 - Coluna estratigráfica do afloramento AJ-03.

Ponto AJ-04 (Coordenadas UTM 710448 E, $8239735 \mathrm{~N}, 510 \mathrm{~m}$ )

Este afloramento possui uma extensão de 150 $\mathrm{m}$ e possui aproximadamente $15 \mathrm{~m}$ de altura, orientação S55E/N50W.

Da base para o topo, camada de $1,50 \mathrm{~m}$ de espessura de arenito avermelhado, granulometria granodecrescente variando de areia grossa para areia média, bastante bioturbado, o que impossibilitou a identificação de estruturas sedimentares. Camada de $1 \mathrm{~m}$ de arenito de granulometria grossa, coloração acinzentado bastante bioturbado com icnofósseis concordantes ao acamamento sedimentar, vale ressaltar que no meio da camada foi identificado uma lente de siltito ferruginoso com estratificação plano paralela de $30 \mathrm{~cm}$ de espessura.

Arenito acinzentado com granulometria variando de areia grossa a areia média com $2,5 \mathrm{~m}$ de espessura, níveis de bioturbação na porção basal, no último metro do pacote de foram identificadas duas lentes de siltitos cinza, ferruginosos e estratificações plano paralelas. Pacote de $2 \mathrm{~m}$ de espessura de arenito cinza com granulometria areia média, o pacote apresenta alta bioturbação na base, já no topo estão presentes estratificações cruzadas acanaladas e marcas onduladas, também foram encontradas finas camadas de restos de vegetais a partir dos $0,60 \mathrm{~cm}$ deste pacote.

Uma fina camada de $0,30 \mathrm{~cm}$ de siltito cinzaesverdeado com marcas onduladas, sotoposta por uma camada de $1 \mathrm{~m}$ de arenito médio, coloração cinza-esverdeada bastante bioturbado; uma outra camada de arenito cinza-esbranquiçado granodecrescente, variando de areia média a silte, com espessura de $0,80 \mathrm{~cm}$ sobrepõe-se, tendo na base marcas onduladas unidirecionais e estratificações cruzadas do tipo hummocky e no topo estratificação plano paralela capeada por uma fina camada ferruginosa irregular de 0,10 $\mathrm{cm}$.

Uma estrutura de escavação delimita muito bem a interface para os pacotes superiores, composta por um arenito médio granodecrescente para areia muito fina, de coloração avermelhada, estratificações cruzadas acanaladas, composto um pacote de $2,5 \mathrm{~m}$ de espessura, onde também foram medidas algumas paleocorrentes, que preferencialmente tem sentido NW/SE. No topo da seção ocorre uma camada de $3 \mathrm{~m}$ de espessura de siltito cinza-esbranquiçado, contendo estratificações plano paralelas e marcas onduladas, com três lentes de arenito médio de coloração amarelada (Figura 5). 

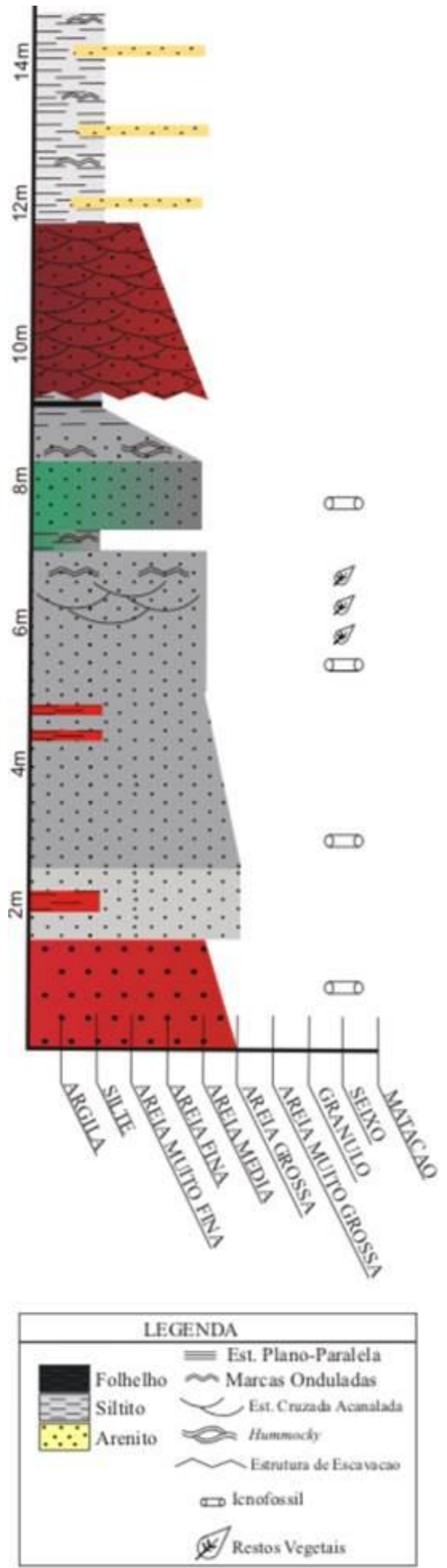

Figura 5 - Coluna estratigráfica do afloramento AJ-04.
Ponto AJ-05 (Coordenadas UTM 708487 E, $8240832 \mathrm{~N}, 507 \mathrm{~m}$ )

O último afloramento descrito possui uma dimensão de aproximadamente 1,20 m de largura e $10 \mathrm{~m}$ de altura, orientado preferencialmente a N60W.
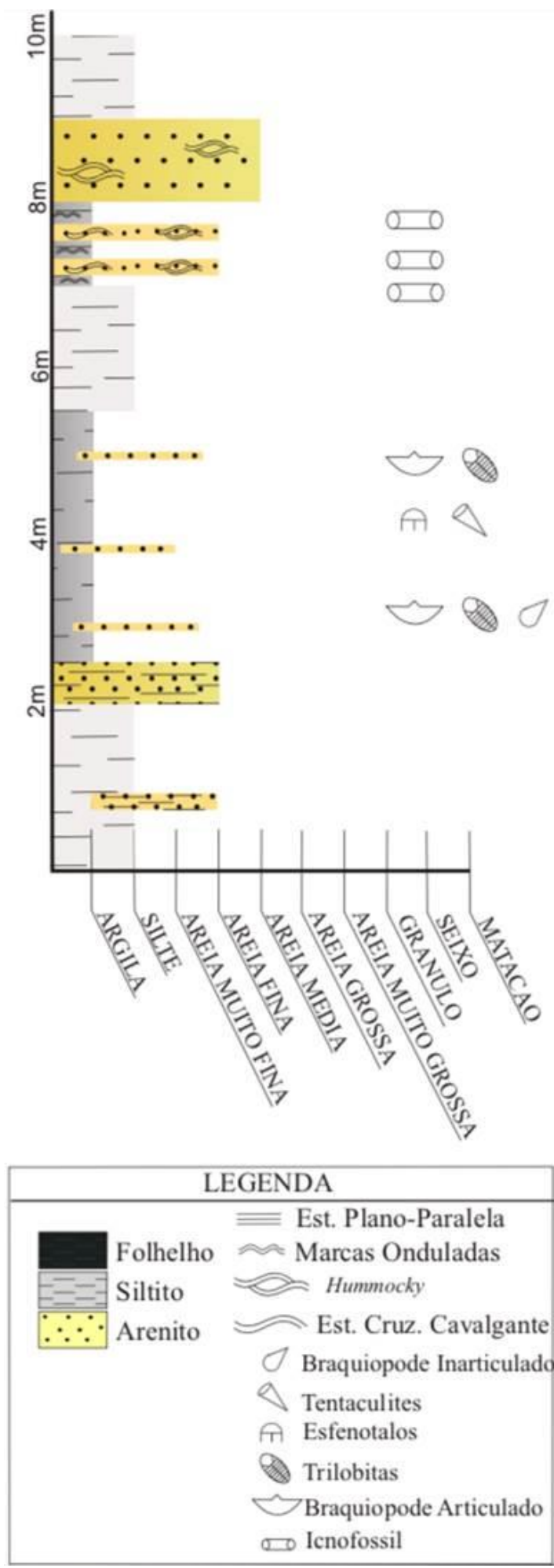

Figura 6 - Coluna estratigráfica do afloramento AJ-05.

A porção inferior aflora uma camada de $2 \mathrm{~m}$ de espessura de siltitos esbranquiçados com estratificações plano paralelas, visto que no primeiro metro deste há uma lente de $0,20 \mathrm{~cm}$ de 
arenito fino amarelado com estratificação plano paralela. Sobreposta por uma camada de aproximadamente $0,50 \mathrm{~cm}$ de arenito fino, coloração amarela-esbranquiçada e estratificação plano paralela, sobreposto por uma camada de folhelhos cinza-clara de $3 \mathrm{~m}$ de espessura, esparsas lentes de arenitos finos e muito finos esbranquiçados são comuns, neste pacote foram encontrados fósseis de lingulídeos, esfenotalos e fragmentos de trilobitas. Sotoposta por uma camada de 1,5 m de siltito esbranquiçado com estratificações plano paralelas.

Acima se assenta pacote de $1 \mathrm{~m}$ de espessura, composto por folhelho cinza com estratificação plano-paralela, marcas onduladas e presença de icnofósseis intercalados com arenitos finos amarelados, estratificações cruzadas do tipo hummocky e estratificação cruzada cavalgante, a proporção dos pacotes argilosos/arenosos e as estruturas presentes nesta seção evidenciam um pacote do tipo flaser. Sobrepondo esta camada, aflora um pacote de $1 \mathrm{~m}$ de espessura de arenito médio de coloração amarelada e estratificação cruzada do tipo hummocky. Capeando este último pacote, uma camada de siltito esbranquiçado de $1 \mathrm{~m}$ de espessura finamente laminado (Figura 6).

\section{DISCUSSÕES}

Os cinco pacotes descritos foram subdivididos em 7 subunidades deposicionais, identificadas como SD-I, SD-II, SD-III, SD-IV, SD-V, SD-VI e SD-VII. Para facilitar a distinção destas subunidades foram delimitadas: a Superfície de Inundação Máxima (SIM), a Superfície de Regressão Forçada (SRF) e a Superfície Transgressiva (ST), bem como as Discordâncias (D) quando aplicáveis.

Segundo Catuneanu (2006), a Superfície de Inundação Máxima (SIM) pode ser definida em uma seção estratigráfica no ponto onde as rochas apresentam a menor granulometria, ou seja, pacotes de folhelhos finamente laminados. Outro fator determinante para a determinação da SIM é que esta linha imaginária delimita o ponto de inflexão entre o Trato Transgressivo Retrogradante e o Trato Regressivo Progradante, além desta possuir abundância fossilífera. Deste modo, a SIM foi definida nos aproximados $5 \mathrm{~m}$ do afloramento AJ-02 e nos $4 \mathrm{~m}$ do afloramento AJ-05, ambos em folhelhos cinza-escuros.

Após a determinação da SIM, é notório que os pacotes inferiores a esta são de natureza retrogradante, predominando rochas de granulometria fina, siltitos na base passando gradativamente para folhelhos no topo, denominado sequência deposicional I (SD-I). Sugere-se para o SD-I um paleoambiente de mar aberto, onde apenas sedimentos finos teriam a capacidade de deposição, além da abundância de fósseis marinhos como trilobitas, moluscos, braquiópodes articulados e inarticulados, dentre outros.

Com a descida isostática do nível do mar, evidenciada pela feição transgressiva retrogradante dos pacotes sotopostos à SIM, estabelece-se uma plataforma continental rasa, possibilitando a geração de fácies alteradas oriundas de aporte continental e aporte marinho (Ribeiro, 2001). A seção SD-II foi caracterizada como um ambiente de frente deltaica fortemente influenciada pela ação das marés, evidenciada pela alternância de pacotes arenosos, siltitos e folhelhos com estratificações cruzadas do tipo hummocky. A presença de icnofósseis do tipo Cruziana fortalecem esta proposta (Walker \& Plint, 1992). Inserido na sequência SD-II há a sequência SD-III (Figura 7), descrita como um único pacote lenticular de arenito médio a muito fino granodecrescente com estratificação cruzada acanalada de pequeno porte, este arenito ainda possui uma base discordante às sequências subjacentes.

Vale ressaltar que de modo geral a sequência SD-II possui uma granocrescência ascendente, na base é comum a ocorrência de folhelhos escuros, siltitos e arenitos muito finos, além dos hummockys, das marcas onduladas e dos icnofósseis; a medida que se vai para o topo desta sequência os arenitos se tornam mais grosseiros, os folhelhos já não são mais encontrados, os icnofósseis não são mais comuns e as estratificações são do tipo cruzada tabular, ou seja, há um aumento na energia do ambiente (Walker \& James 1992).

A sequência SD-IV consiste em pacotes de arenitos avermelhados intensamente bioturbados com frequentes camadas irregulares de ferro, esses arenitos ocorrem nos afloramentos AJ-02, AJ-03 e AJ-04. O contato entre SD-II e SD-IV é erosivo, fazendo com que a Superfície de Regressão Forçada (SRF) seja posicionada entre estes (Figura 8). Outros fatores que influem tal posicionamento para esta superfície é o contraste de litologias entre as sequências deposicionais e a evidente descida do nível do mar, como discutido por Catuneanu (2006). 

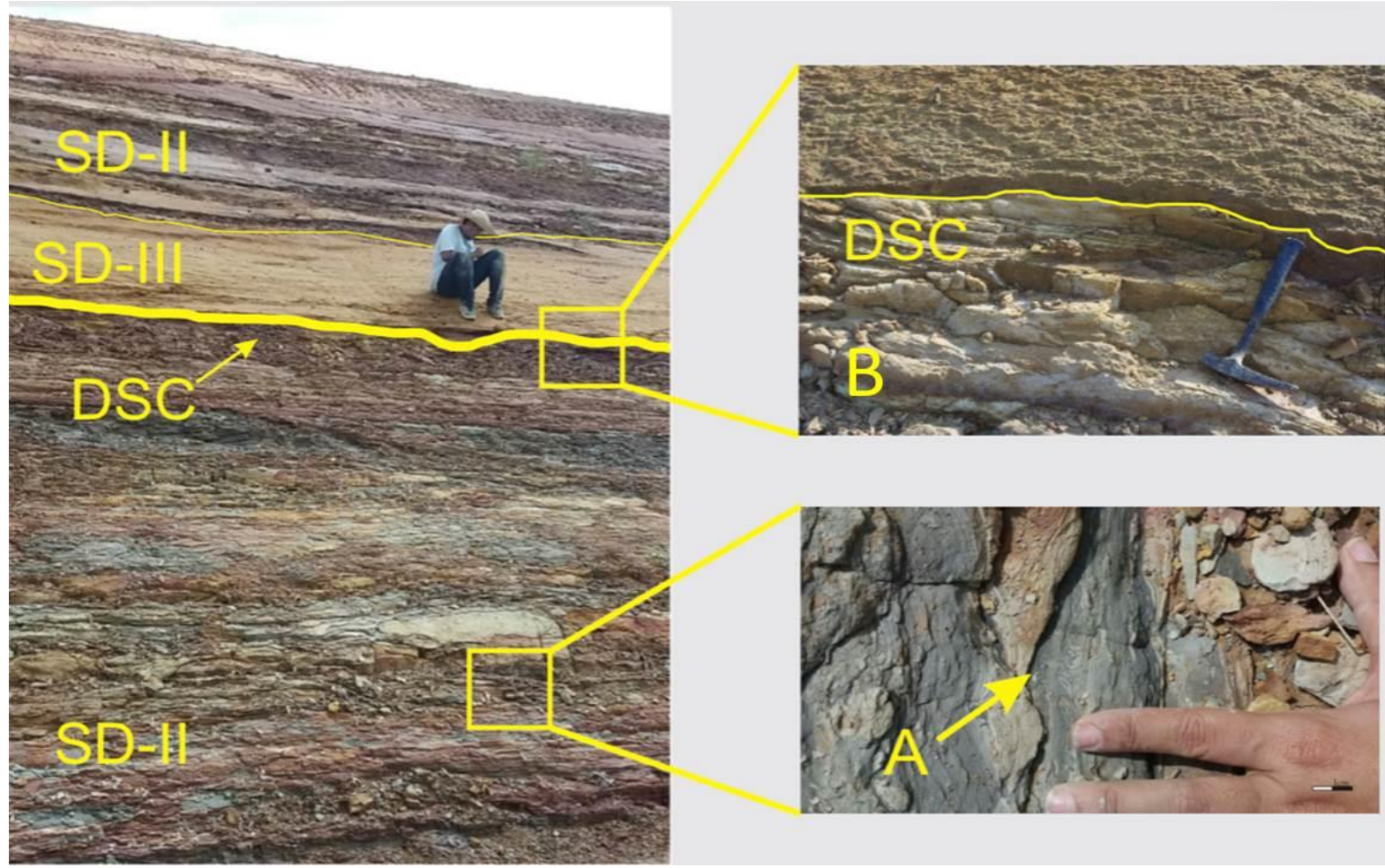

Figura 7 - Visão geral da sequência SD-II, intercalada com a sequência SD-III de forma discordante denominada DSC (vide detalhe em B); Icnofósseis do tipo Cruziana indicado na seta A.

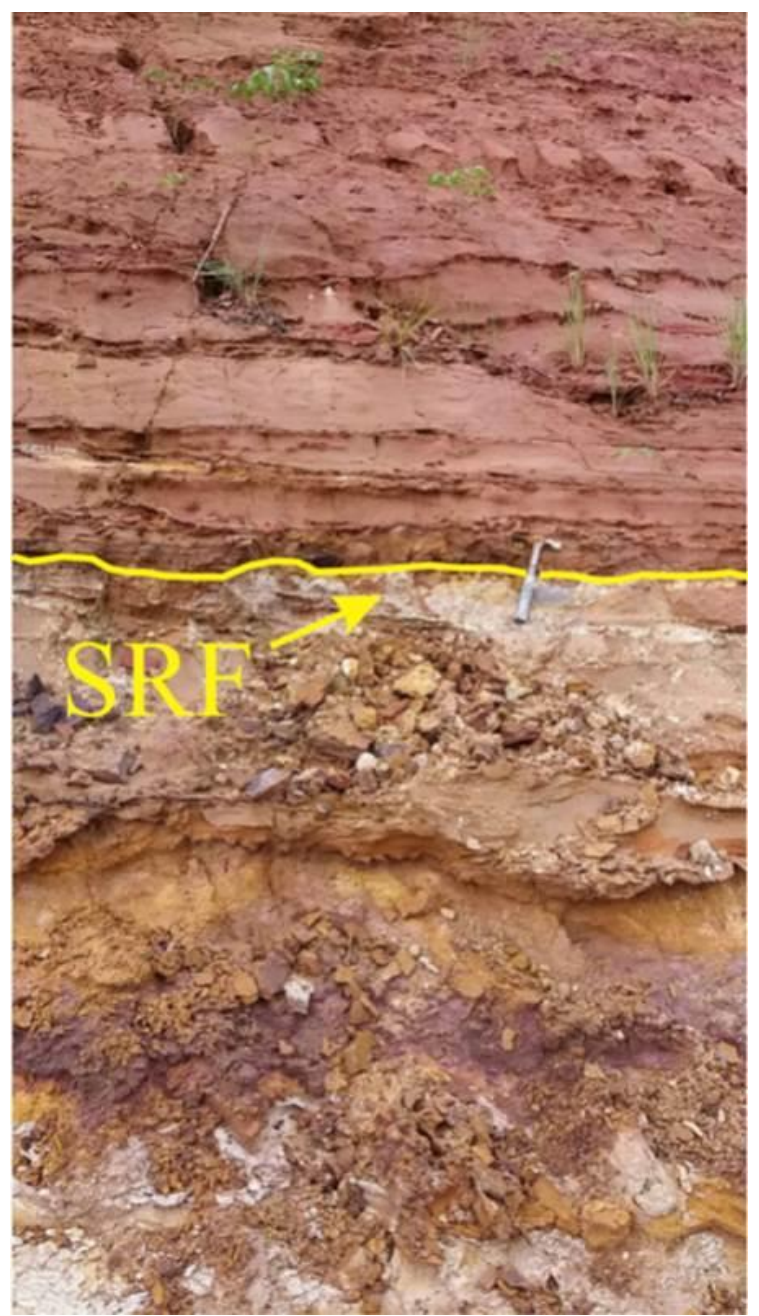

Figura 8 - Superfície de Regressão Forçada (SRF) delimitada entre as sequências SD-II e SD-IV.
Com a descida forçada do nível do mar, a plataforma continental fica exposta à erosão aérea, levando a geração de vales incisos, estes vales por sua vez, são preenchidos pelos arenitos avermelhados com estratificações cruzadas acanaladas unidirecionais, aqui individualizadas na sequência SD-IV (Della Fávera, 2000).

Sobrepondo as sequências inferiores, a seção SD-V foi classificada como uma planície deltaica com diversos rompimentos contínuos de diques marginais, isso pode ser atestado pelos pacotes heterolíticos presentes no afloramento AJ-03 (Figura 9) e AJ-04, arenitos com estratificação cruzada tabular, lentes de conglomerados monomíticos indicando uma alta energia no sistema, e siltitos com estratificação plano-paralela bioturbados indicam uma baixa energia, isto é, alternância sistemática de energia (Walker \& Plint, 1992). Outro fator que corrobora para a caracterização dessa sequência como uma planície deltaica consiste na ocorrência de finas camadas de restos de vegetais (cutículas de Spongiophyton nanum segundo Vieira et al., 2018). Não foi possível estabelecer um padrão tafonômico para tais cutículas pois as lentes são irregulares e os fósseis não possuem um padrão de deposição (Matsumura et al., 2017) sendo que a preservação fossilífera se deu justamente por esse sufocamento das paleo-biotas costeiras. 

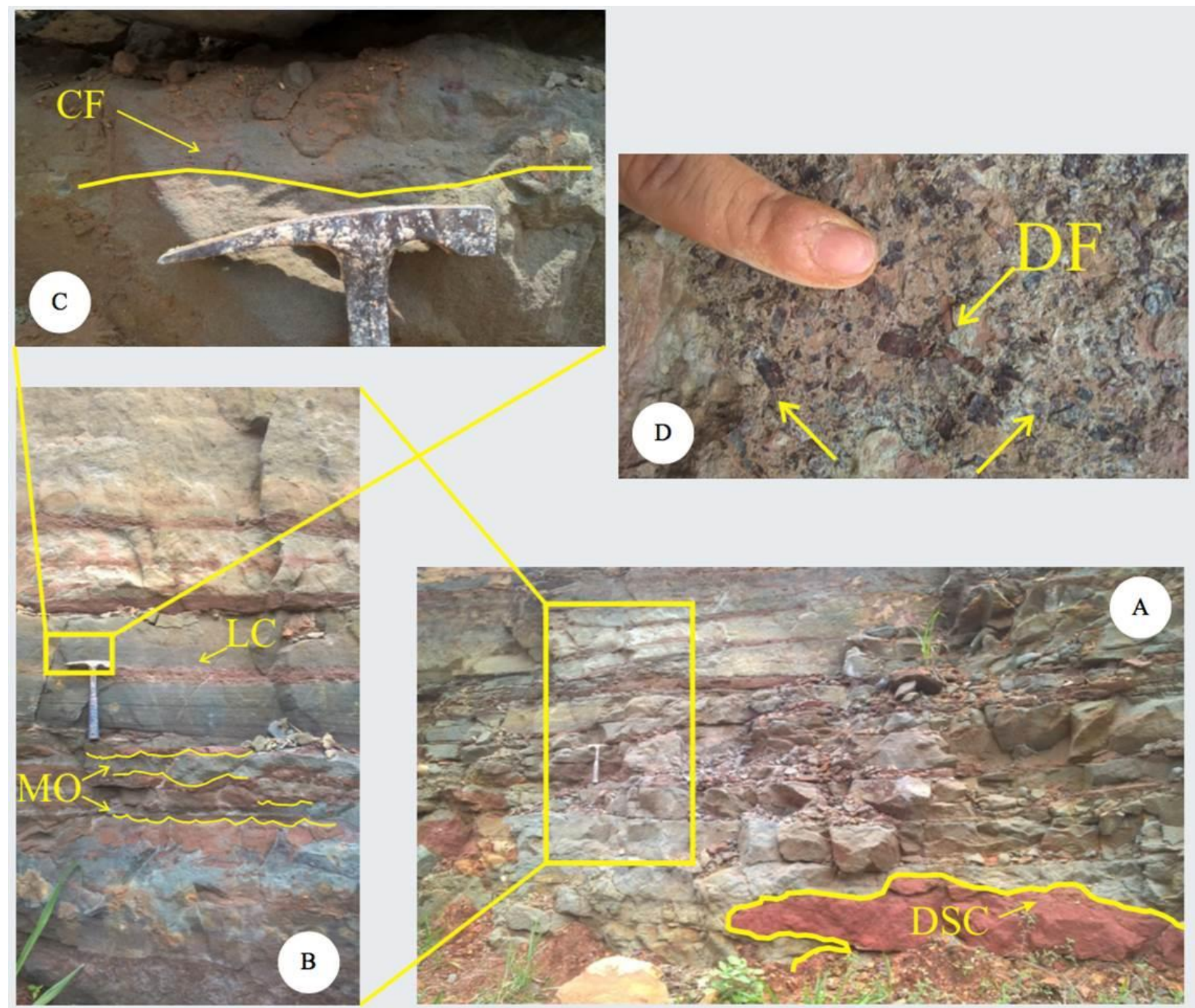

Figura 9 - A: Visão parcial do afloramento AJ-03, onde é possível observar a discordância entre as sequências SD-V e SD-VI; B: Consecutivos depósitos heterolíticos de rompimento de diques marginais, onde se pode ver as marcas onduladas em arenitos e siltitos (MO) e a lente de conglomerado (LC); C: Camada de restos de vegetais em afloramento (vice detalhe em D).

Sobrepondo as seções subjacentes, foi caracterizada a seção SD-VI que também é descrita como um sistema de canal discordante, ocorrendo no afloramento AJ-04 (Figura 10), devido à feição granodecrescente (areia média à areia muito fina) e a presença de estratificações cruzadas acanaladas. Sobreposta a todas as sequências e identificada unicamente neste ponto, a sequência SD-VII, tem características paleoambientais marinhas costeiras, o que faz que a Superfície Transgressiva (ST) seja posicionada exatamente neste ponto, com uma subida súbita do nível do mar.

A estratigrafia proposta por Andrade e Camarço (1980) para a sub-bacia Alto Garças sugere uma sequência restrita ao estado de Goiás, o denominado Membro Médio. Este teria origem em um ambiente deltaico, com arenitos avermelhados de planícies deltaicas, depósitos de canais e camadas contendo muita matéria orgânica proveniente de planícies de inundações deltaicas. Melo (1988) reafirma esta proposta de ambiente deltaico, denominando essa supersequência de Chapada unidade 3. Ainda, segundo Andrade \& Camarço (1980), nos estados de Mato Grosso e Mato Grosso do Sul, essa unidade seria inexistente sendo o membro inferior (Unidade Chapada 2) em contato direto com o membro superior (Unidade Chapada 4).

No entanto, os dados coletados em Jaciara indicam paleoambiente deltaico, onde as seções SD-IV, SD-V e SD-VI representam tal subambiente, sendo que SD-IV vem a ser uma fase de vales incisos devido a descida súbita do nível do mar, SD-V caracteriza a planície deltaica, evidenciada pelas sequências heterolíticas associadas aos restos vegetais e SD-VI corresponde ao canal isolado deste delta (Figura 11), ambientes similares os quais são descritos na Unidade Chapada 3. 


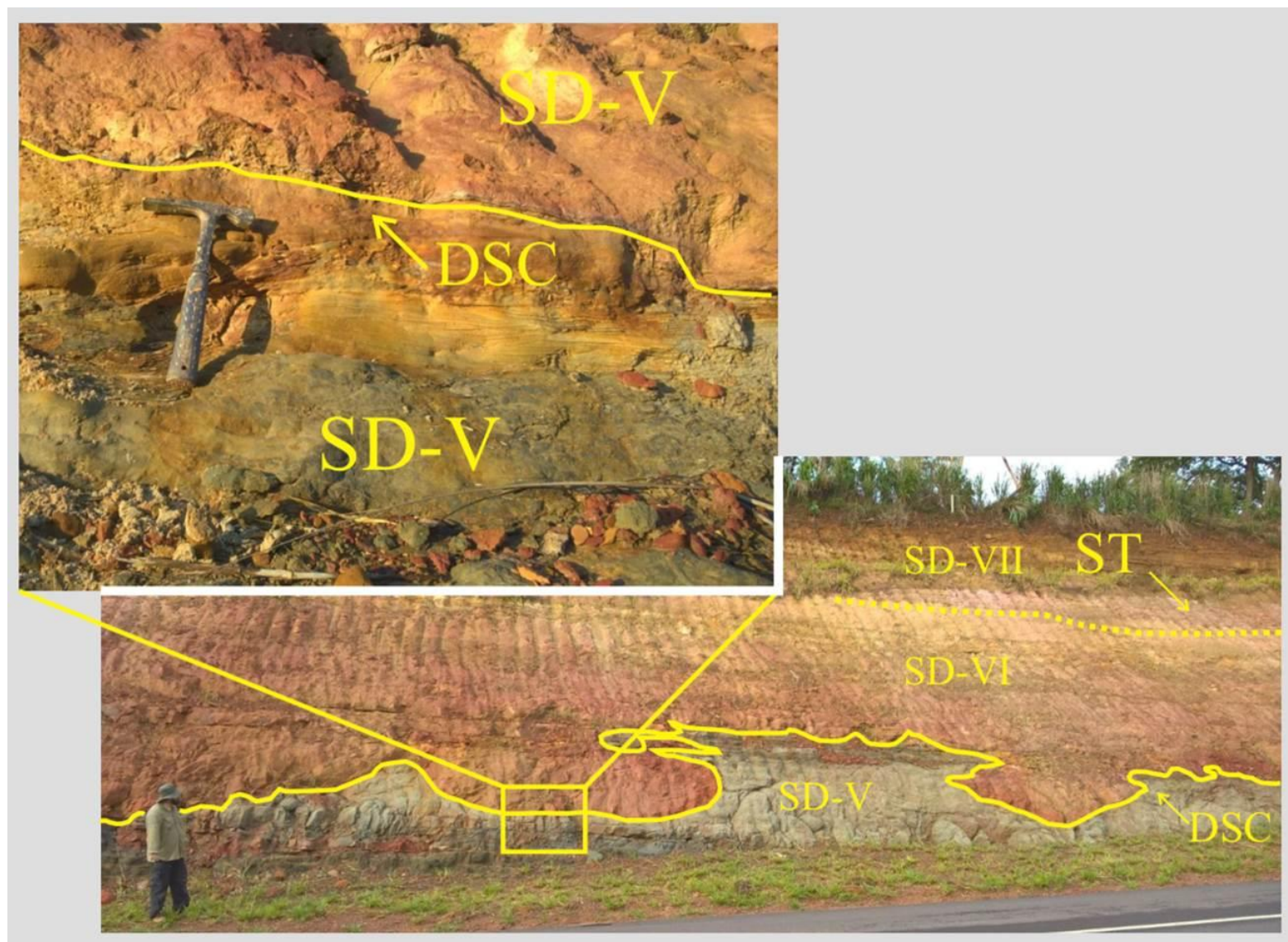

Figura 10 - Visão do afloramento AJ-04 onde se pode ver a discordância (DSC) entre as sequências SD-V e SD-VI (vide detalhe em B). Também é possível observar a Superfície de Transgressão (ST) entre as unidades SD-VI e SD-VII.

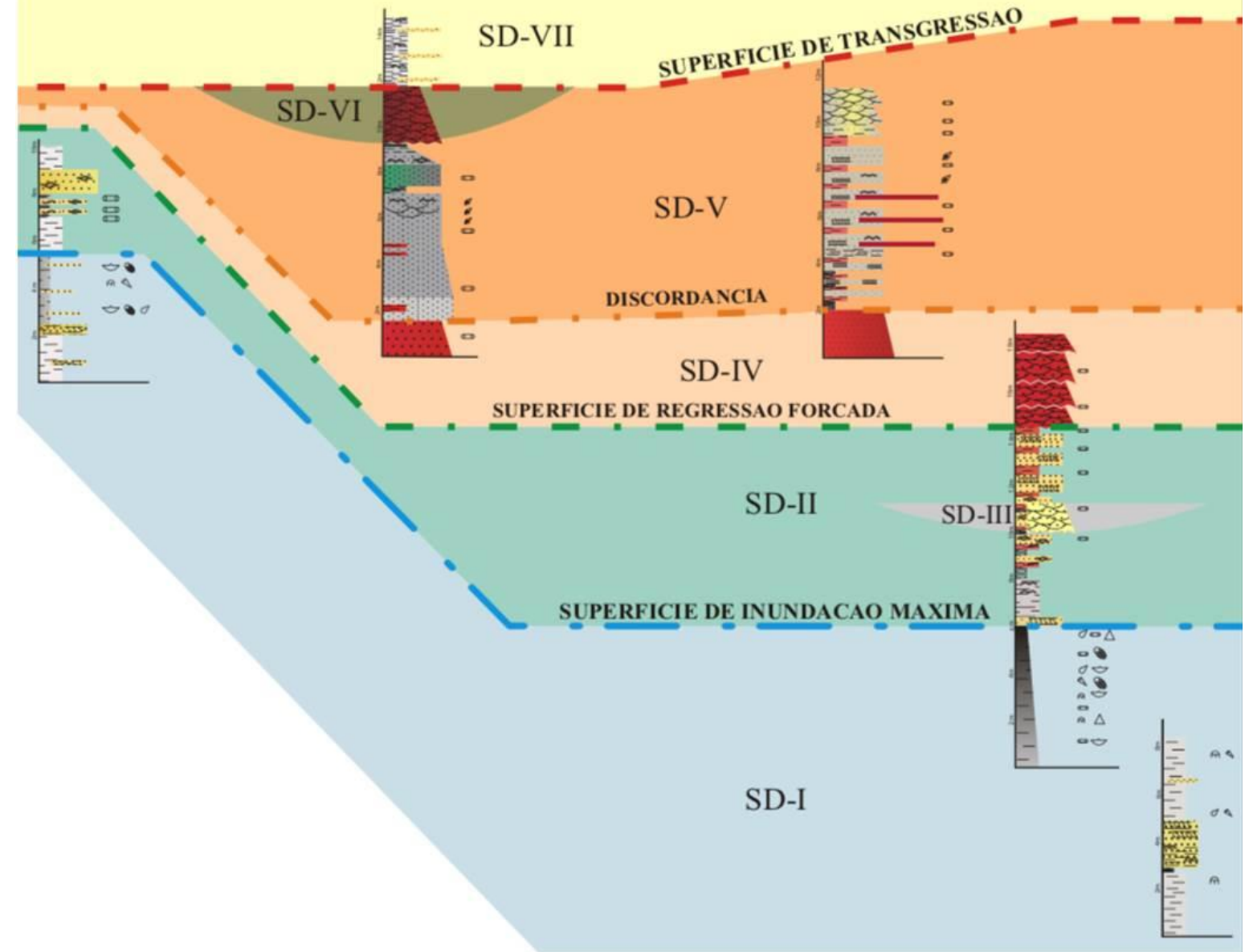

Figura 11 - Correlação entre os perfis levantados da região de Jaciara, com as devidas proporções, sequências deposicionais e superfícies traçadas. 


\section{CONCLUSÃO}

A partir das associações de fácies descritas na região de Jaciara-MT e discutidas no presente trabalho é possível concluir que a estratigrafia proposta por Andrade \& Camarço (1980) e posteriormente formalizada por Melo (1988) para a sub-bacia de Alto Garças deve ser revisada, a fim de conter as fácies deltaicas aqui descritas ao flanco aflorante nos estados de Mato Grosso e Mato Grosso do Sul.
A descrição de tal ambiente deposicional na porção norte da sub-bacia Alto Garças é inédita em subsuperfície e superfície (Andrade \& Camarço, 1980; Melo, 1988; Mauller et al., 2007). Dessa forma, a descrição da Unidade Chapada 3 nesta região amplia as possibilidades de correlações cronobioestratigráficas para o Devoniano Médio a Superior da sub-bacia Alto Garças.

\section{REFERÊNCIAS}

ANDRADE, S.M. \& CAMARÇO, P.E.N. Estratigrafia dos sedimentos devonianos do flanco nordeste da Bacia do Paraná. In XXXI CONGRESSO BRASILEIRO DE GEOLOGIA, 5, 1980, Balneário de Camboriú. Anais... Santa Catarina: Sociedade Brasileira de Geologia, 1980, p 2828-2834.

ASSINE, M.L. Aspectos estratigráficos das sequências précarboníferas da Bacia do Paraná no Brasil. São Paulo, 1996. 206p. Tese (Doutorado em Geociências) - Instituto de Geociências, Universidade de São Paulo.

BOSETTI, E.P. Paleontologia do devoniano dos Campos Gerais. In: MELO, M. S.; MORO, R. S.; GUIMAR ÃES, G.B. (Coords), Patrimônio natural dos Campos Gerais do Paraná. Ponta Grossa: Financiadora Editora Universidade Estadual de Ponta Grossa, p. 33-47, 2007.

BOUCOT, A.J. Malvinokaffric Devonian marine community distribution and implications for Gondwana. Anais da Academia Brasileira de Ciências, v. 43, p 23-49, 1971.

CARBONARO, F.A., \& GHILARDI, R.P. Fósseis do Devoniano de Goiás, Brasil (Sub-bacia Alto Garças, Bacia do Paraná). Papéis Avulsos de Zoologia, v. 56, n. 11, p. 135-149, 2016.

CATUNEANU, O. Principles of sequence stratigraphy: Elsevier, Amsterdam, 375 p. 2006.

DELLA FÁVERA, J. C. Fundamentos de Estratigrafia Moderna. Rio de Janeiro: Eduerj, 278p., 2000.

FERNANDES, L.A. \& COIMBRA A.M. O Grupo Caiuá (Ks): Revisão estratigráfico e contexto deposicional. Revista Brasileira de Geociências. v. 24, n. 3, p. 164-176, 1994.

FRANÇA, A.B. \& POTTER, P.E. Estratigrafia, ambiente deposicional e análise de reservatório do Grupo Itararé (Permocarbonífero), Bacia do Paraná (Parte 1). Boletim de Geociências da Petrobrás, v. 2, n. 2/4, p. 147-191, 1988.

GRAHN, Y.; MENDLOWICZ MAULLER, P.; PEREIRA, E.; LOBOZIAK, S. Palynostratigraphy of the Chapada Group and its significance in the Devonian stratigraphy of the Paraná Basin, south Brazil. Journal of South American Earth Sciences, v. 29, p. 354-370, 2010.

MATSUMURA, W.M.K.; GHILARDI, R.P.; RIBEIRO, V.R.; NETA, N.D.L.S.; FRAZÃO, N.L.D.S.; SOUZA, B.O. Novos registros de Spongiophyton no Devoniano do Mato Grosso, MT (Sub-bacia de Alto Garças). In: XXV CONGRESSO BRASILEIRO DE PALEONTOLOGIA, 32, 2017, Ribeirão Preto. Resumo... São Paulo: Sociedade Brasileira de Paleontologia, 2017, p. 194.

MELO, J.H.G. The Malvinokaffric Realm in the Devonian of Brazil. In: McMillan, N.J.; Embry, A.F. \& Glass, D.J. (Coordenadores), Devonian of the World: Proceedings of the 2nd International Symposium on the Devonian System. Canadá: Canadian Society of Petroleum Geologists, p. 669-703, 1988.
MILANI, E.J. Evolução tectono-estratigráfica da Bacia do Paraná e seu relacionamento com a geodinâmica fanerozoica do Gondwana sul-ocidental. Porto Alegre, 1997. 2v. Tese (Doutorado), Universidade Federal do Rio Grande do Sul.

MILANI, E.J.; MELO, J.H.G.; SOUZA, P.A.; FERNANDES, L.A.; FRANÇA, A.B. Bacia do Paraná. Boletim de Geociências da Petrobrás. Rio de Janeiro: Petrobras, p. 265287, 2007

QUADROS, R. Braquiópodes devonianos do afloramento Tope de Fita - Chapada dos Guimarães, Mato Grosso, Brasil. Porto Alegre, 1979. Tese (Mestrado em Ciências Naturais) - Universidade Federal do Rio Grande do Sul.

RAMOS, A.N. Aspectos paleo-estruturais da Bacia do Paraná e sua influência na sedimentação. Boletim Técnico da Petrobrás, v. 13, n. 3-4, p. 85-93. 1970

RENNE, P.R.; ERNESTO, M.; PACCA, I.G.; COE, R.S.; GLEN, J.; PRÉVOT, M.; PERRIN, M. Rapid eruption of the Paraná flood volcanism, rifiting of southern Gondwanaland and the Jurasssic-Cretaceous boundary. Science, v. 258, p. 975-979, 1992.

RIBEIRO, H.J.P. Estratigrafia de Sequências: fundamentos e aplicações. Porto Alegre, Rio Grande do Sul, Brasil. Editora Unisinos, 2001.

SCOTESE, C.R. \& McKERRO, W.S. Revised world maps and introduction. The Geological Society Memoirs, v. 12, p. 1-21, 1990.

SIMÕES, M.G. \& GHILARDI, R.P. Protocolo Tafonômico/Paleo autoecológico como Ferramenta nas Análises Paleossinecológicas de Invertebrados: Exemplos de Aplicação em Concentrações Fossilíferas do Paleozóico da Bacia do Paraná, Brasil. Pesquisas em Geociências, v. 23, n. 2, p. 3-13, 2000.

VIEIRA, G.A.G.; GHILARDI, R.P.; CAMINHA S.A.F.S.C.; RIBEIRO, V.R. Descrição de uma fáceis Tafonômica vegetal do Grupo Chapada (Devoniano da Bacia do Paraná), município de Jaciara/MT. In: CONGRESSO NACIONAL DE BOTÂNICA, 2018, Cuiabá. Resumo... Mato Grosso: Sociedade Brasileira de Botânica, 2018, p. s/n.

WALKER, R.G. \& PLINT. A.G. Wave and storm dominated shallow marine systems: In WALKER, R.G. \& JAMES, N.P. Facies Models - Response to sea level change, Geological Association of Canada, Canadá, p. 219-238, 1992.

WALKER, R.G. \& JAMES, N.P. Fácies models - Response to sea level changes. Ontario: Geological Association of Canada, 1992.

Submetido em 23 de novembro de 2018 Aceito em 18 de setembro de 2019 